\title{
Ueber den Einfluss der Körperbewegung auf die Magenverdauung.
}

\author{
Von \\ Prof. Dr. med. F. Trangl \\ in Budapest.
}

\section{I.}

Die älteste und von der Mehrzahl der Aerzte angenommene Ansicht tiber den Einfluss der Körperbewegung auf die Verdaunng ist wohl die, dass eine mässige Bewegung nach der Mahlzeit am zuträglichsten ist. Das sagt ja auch der bekannte alte Spruch: „post coenam stabis aut mille passus ambulabis". Suchen wir aber einen Beweis für die Richtigkeit dieser Annahme, so dürften wir in der ganzen Literatur kaum einen finden. Thatsächlich existiren nur spärliche Beobachtungen und Untersuchungen ïber diese auch vom praktischen Standpunkte sehr wichtigen Frage.

Die ersten Versuche und zwar an Thieren seheint L o u is Villa in im Jahre 1849 angestellt zu haben. Er fütterte zwei gleich grosse Hunde mit derselben Quantität Futter und liess dann den einen laufen und den anderen ruhig liegen. Nach einer gewissen Zeit tödtete er sie und fand bei dem Hunde, welcher lief, das aufgenommene Futter fast noch unverändert vor, während bei dem anderen sich bereits Chymus gebildet hatte ${ }^{1}$ ). Nach der Arbeit Villa i n's vergingen, wie ich aus der mir zugänglichen Literatur ersehe, wieder Jahrzehnte, bis die Frage neuerdings experimentell gepriift wurde. Inzwischen fand die alte Lehre auch noch durch Ranke's Untersuchungen über die Blutvertheilung beim Thätigkeitswechsel der Organe eine Bestärkung, da durch diese bewiesen wurde, dass die Verdaungsorgane während der Verdauung einen stärkeren Blutzufluss haben, ebenso wie die thätigen

1) Citirt nach Salvioli siehe weiter unten. 
Muskeln. Es war also der Gedanke sebr naheliegend, dass durch die Muskelthätigkeit bei den Körperbewegungen, den Verdauungsorganen Blut entzogen wird. - Forster ist der erste, der auf Grund von Versuchen, die in seinem Laboratorium C. Hestermann angestellt hat, der Ansicht Ausdruck verleiht, „dass die Verdaungszeit, wie wahrscheinlich auch die Ausnützungsgrösse verschiedener Speisen die gleiche bei der Ruhe, wie bei der Arbeit des consummirenden Menschen sei ${ }^{1}$ ).

Im Jahre 1888 hat J. Cohn ${ }^{2}$ ) unter Rossbach's Leitung Versuche an Hunden angestellt, um den Einfluss mässiger Körperbewegung anf die Magenverdauung zu bestimmen. Die Hunde erbielten eine bestimmte Probemahlzeit - (125 gr frischen Schabfleisches und $150 \mathrm{~cm}^{3}$ Wasser) - die nach 15 stündiger Carenz verabreicht wurde. Dann wurden die Thiere abwechselnd entweder der Ruhe überlassen oder auf einen 2 stündigen Spaziergang mitgenommen. 2-5 Stunden nach Aufnahme der Probemahlzeit wurde der Magen durch eine Hebersonde mit $300 \mathrm{~cm}^{3}$ Wasser ausgespült. Der auf diese Weise gewonnene verdinnte Magensaft wurde auf seine verdauende Kraft, seinen Salzsäure-, Milchsäureund Peptongehalt gepriift. Die zahlreichen Versuche, die $\mathrm{Coh} \mathbf{n}$ an 3 Hunden ausführte, ergaben, dass, durch Bewegung unmittelbar nach der Nahrungsaufnahme die Magenverdauung beeinflusst wird und dass dieser Einfluss in Verlangsamung und Verzögerung der Verdaung besteht."

$\mathrm{Zu}$ ganz entgegengesetzten Resultaten gelangte Streng ${ }^{3}$ ) sowohl beim Menschen als beim Hunde. Streng gab seinen Hunden $25 \mathrm{gr}$ Carne pura in $300 \mathrm{~cm}^{3}$ warmen Wassers suspendirt; danach

1) J. Forster, Ernährung und Nahrungsmittel in Pettenk ofer u. Voit's Hdb. der Hygiene I. 1. p. 113. Forster beruft sich an dieser Stelle bezüglich der Hestermann'schen Versuche auf seinen Artikel „Kost des Menschen" in Liebig-Fehling's "Handwörterbuch der Chemie “. Dieser Artikel enthält jedoch, wie J. Cohn angiebt - das Liebig-Fehling'sche Werk stand mir nicht zur Verfügung - keine näheren Angaben über die Art und Ergebnisse dieser Versuche.

2) J. Cohn, Ueber den Einfluss mässiger Körperbewegung auf die Verdauung. Deutsches Archiv f. klin. Medic. Bd. XLIII. pag. 239.

3) Streng, Ueber den Einfluss körperlicher Bewegung auf die Magenverdauung. Deutsche med. Wochenschr. 1891. p. 54. 
mussten sie einmal 3 Stunden in absoluter körperlicher Ruhe zubringen, das andere mal tüchtige Bewegung machen. Nach 3 Stunden wurde der Magen mit der Magenpumpe - ohne vorheriges Eingiessen von Wasser - seines Inhaltes völlig entleert und der letztere chemisch untersucht. Im Ganzen wurden an zwei Hunden 38 Versuche angestellt. Ausserdem wurden an 3 Männern mit gesundem Magen 25 Versuche ausgeführt. Diese erbielten eine Probemahlzeit - $(200 \mathrm{gr}$ Schabflejsch, 1 Brödchen, 1 Teller Bouillon, 2 Löffel Kartoffelbrei) - und verblieben dann entweder in Ruhe oder machten theils Bewegung am Ergostaten, theils gingen sie spazieren. Nach $4 \frac{1}{2}$ Stunden wurden sie mit der Magensonde ausgehebert. Sowohl die Versuche an den Hunden als die am Menschen ergaben tibereinstimmend, dass die Magenthätigkeit in keiner Weise davon beeinflusst wird, ob der Körper Muskelbewegungen ansgesetzt wird oder ob er absolute Ruhe einhält."

Salvioli ${ }^{1}$ ) hat ebenfalls an Hunden experimentirt. In den meisten Versuchen hat er Magenfistelthiere verwendet; in einigen hat er den Magen zum Zwecke der Untersuchung seines Inhaltes durch subeutane Apomorphininjectionen entleert. Die gewïnschte Körperbewegung machten die Thiere in einem Tretrade, meist $3 \mathrm{~km}$ per. Stunde; am längsten liefen sie 5 Stunden $=45 \mathrm{~km}$. Die Resultate dieser Versuche waren die folgenden: Die körper liche Bewegung setzt die Menge des producirten Magensaftes bedeutend herab; die Acidität, der gesammte Chlorgehalt des Magensaftes ist vermindert. Dem entsprechend stört die körperliche Ermiidung auch die Magenverdaung, da der während derselben producirte Magensaft viel von seinem Verdauungsvermögen verloren hat. Doch sind diese Verdauungstörungen nur vorïbergehend, denn 2 Stunden nach der Körperbewegnng wird wieder ein normaler Magensaft secernirt. Ausserdem überzengten S. zwei Versuche davon, dass die aufgenommene Nahrung, wenn auch unverdaut, durch die Körperbewegung aus dem Magen schneller in den Darm befördert wurde.

Noch zwei Arbeiten giebt es - so weit ich die Literatur durchsuchen konnte - die den Einfluss der Körperbewegung auf

1) Salvioli, Influence de la fatigue sur la digestion stomacale. Archives italiennes de biologie. 1892. T. XVII. p. 248. 
die Magenverdaung behandelten, die Dissertation von W. Spiri ${ }^{1}$ ) und die kurze Mittheilung von H. Surmont et Brunelle ${ }^{2}$ ). Sp. untersuchte an sich und noch einem gesunden Manne genau 60 Minuten nach Aufnahme eines Ewald'schen Probefrühstückes den durch Expression nach Boas entleerten Mageninhalt und fand, „dass bei Ruhe der höchste Aciditätsgrad erreicht wird, die Peptonund Propeptonmengen die grössten sind, die Motilität dagegen die geringste ist; bei mässiger Bewegung die Säuremenge abnimmt, ebenso die Menge der Propeptone und Peptone und die Motilität des Magens sich steigert, während alle übrigen Factoren der Magenverdaung gleich bleiben, bei eigentlicher Arbeit ebenfalls die Säuremenge und die Menge der Peptone wie bei mässiger Bewegung fällt, die Motilität zunimmt, während die übrigen Magenfunktionen unverändert bleiben und ausnahmsweise eine gänzliche Aufhebung der Magenverdauung in der ersten Stunde nach dem Ewald'schen Probefruihstück eintritt."

S a r mont und Branelle fanden bei Hunden, dass die Körperbewegung gleich nach der Nahrungsaufnahme die Motilität des Magens nicht besonders beeinflusst; allerdings geben sie nicht an, wie sie sich davon überzeugt haben. Dagegen ist nach ihnen die Säureproduction bedeutend erhöht.

Wäbrend fast in allen angeführten Publicationen nur ein Theil der Verdauungsarbeit der Gegenstand der experimentellen Prüfung war, hat neuestens $\mathrm{S}$. R o s e $\mathrm{n} \mathrm{b}$ e $\mathrm{rg}^{3}$ ) mit einer Reihe sehr exakter Versuche, die er im Zuntz'schen Laboratorium anstellte, die Frage entschieden, wie die Gesammtverdaunng, die Ausnützung der aufgenommenen Nabrungsstoffe durch die Körperbewegung beeinflusst wird. R. liess sein Versuchsthier, eine Hündin, auf der $\mathrm{Z} \mathrm{untz}$ - L e hman n'schen Tretmïhle meist.vier Stunden hintereinander arbeiten. Die dabei verrichtete Arbeit war verschieden gross, doch immer eine recht anstrengende. In einem Theil der

1) W. Spirig, Ueber den Einfluss von Ruhe, mässiger Bewegung und körperlicher Arbeit auf die normale Magenverdauung des Menschen. Diss. inaug. Bern. 1892.

2) Surmont et Brunelle, De l'influence de l'exercise sur la digestion gastrique. (Compt. rend. de la soc. de biologie. 1894. pag. 705.)

3) S. Rosenberg, Ueber den Einfluss körperlicher Anstrengung auf die Ausnützung der Nahrung. (Dieses Archiv Bd. 52. p. 401.) 
Ueber den Einfluss der Körperbewegung auf die Magenverdauung. 549

Versuche fiel die Arbeit in die Zeit der Magenverdaunng, im anderen in die der Darmverdauung. Die Nahrung des Thieres bestand aus magerem Pferdefleisch, Schweineschmalz und Reis. Im Kothe wurde der $\mathrm{N}$ und das Fett bestimmt. Das Ergebniss dieser Versuche war, "dass beim verdauungsgesunden Hunde die Ausnuitzung der Nahrung ganz unabhängig davon ist, ob das Thier sich während der Verdauung in Rube befindet oder eine sehr energische Arbeit leistet." $R$. hält es für wahrscheinlich, dass dieser Satz auch für den Menschen giiltig ist.

Vor R o s e n berg haben schon Grande a und Leclerc und E. Wolff ähnliche, wenn auch nicht so ausführliche Versuche an Pferden angestellt.

Grandea und Le clerc ${ }^{1}$ ) haben in dem Laboratorium der Comp. générale des voitures in Paris eine Futtermischung, welche den Pferden der genannten Gesellschaft gegeben wurde, auf Werth und Brauchbarkeit geprift und unter ihren zahlreichen Versuchen auch den Einfluss der Arbeit untersucht. Die Grösse der geleisteten Arbeit wurde an einem Göpel mit Dynamometer bestimmt. Die Versuche an 3 Pferden ergaben, dass eine längere Zeit fortgesetzte Bewegung oder eine vermehrte Tagesarbeit eine Verdauungsdepression zur Folge hat, welche für die gesammte organische Substanz bei der Bewegung im Schritt 1-2\%, im Trab $3-4 \%$ beträgt. Auch scheint auf die Grösse der Depression weniger die etwas erhöhte Arbeitsleistung als vielmehr die Art der Bewegung von Einfluss zu sein. Die Verdaungsdepression ist bei rascherem Gange - Trabe - sowohl mit als olne Arbeitsleistung bedeutend grösser als bei der Bewegung im Schritt.

E. $W 01 f^{2}$ ) ist bei seinen Versuchen in Hohenheim zu anderen Resultaten gelangt, trotzdem die Versuchsanordnung eine ähnliche war wie die der französischen Autoren. Das Resultat seiner Versuche lautet dahin, dass „die Steigerung der Tagesarbeit bis zu einer gewissen Grenze dic Verdaung des Futters nicht con-

1) Grandeau et Leclerc, Etudes expérimentales sur l'alimentation du cheval de trait. Paris, Berger-Lévrault. 1882. -- Deuxième mémoire. 1883. - (Citirt nach E. Wolff.)

2) E. Wolff, Grundlagen für die rationelle Fütterung des Pferdes. Berlin. P. Parey 1886 und Grund. f. die rat. Fütt. des Pferdes. - Neue Beiträge. Ebenda 1887. 
stant nach bestimmten Richtungen hin beeinflusst, wenn die Fortbewegung des Pferdes hierbei stets im gleichen langsamen Schritt am Göpel erfolgt." - Das von den Pariser Versuchen abweichende Resultat erklärt W. mit der verschiedenen Individualität der Versuchsthiere; möglicherweise "spiele auch die verschiedene Fütterungsweise dabei eine Rolle."

Aus dieser Uebersicht über die einschlägige Literatur dürfte es zur Genüge hervorgehen, dass wir über den Einfluss der Körperbewegung anf die Verdanung kaum etwas Bestimmtes wissen, weder was die Gesammtausnitzung der Nahrung noch was die verschiedenen Verdauungsvorgänge in den einzelnen Abtheilungen des Magen-Darmkanales betrifft. Einerseits gelangten die verschiedenen Forscher bei derselben Thiergattung zu widersprechenden Resultaten, anderseits ist es ja noch gar nicht festgestellt wie weit man in dieser Frage von einer Thierspecies auf eine andere folgern kann, da unsere diesbezüglichen vergleichend-physiologischen Kenntnisse noch ziemlich lückenhaft sind.

Dieser Umstand gab auch die Veranlassung zu den Untersuchungen, über die im Folgenden berichtet werden soll. Sie wurden za dem Zwecke angestellt, um den Einfluss der Körperbewegung auf die Verdauungsvorgänge im Magen des $P$ ferdes kennen zu lernen. Bei diesem Thiere wurde dies meines Wissens bisher iberhaupt noch nicht untersucht und ich unterzog mich auf Anregung des Herrn Medizinalrath Prof. Dr. Ellenberger umso bereitwilliger dieser Aufgabe, als ja vor allem die interessante Frage zu entscheiden war ob, sich die Verdauungsvorgänge im Magen eines Pflanzenfressers während der Körperbewegnng ebenso verhalten, wie die des Hundes oder des Menschen und anderseits diese Frage auch vom praktischen Standpunkte der rationellen Fitterung des Pferdes von Wichtigkeit ist. Die Untersuchungen habe ich noch vor 4 Jahren im physiologischen Institute der Dresdener thierärztlichen Hochschule begonnen und grösstentheils durchgeführt und dann später so weit es möglich war in meinem Institute abgeschlossen. Es ist mir eine angenehme Pflicht, Herrn Medizinalrath Prof. Dr. ElI e n b e r g e r auch an dieser Stelle für sein liebenswürdiges Entgegenkommen und die überaus liberale Weise, mit der er mir zu den Untersuchungen sein Institut und das kostspielige Thiermaterial überliess, meinen verbindlichsten Dank auszusprechen. 
Ueber den Einfluss der Körperbewegung auf die Magenverdauung. 551

II.

Von den Methoden welche bei unseren Untersuchungen in Betracht kommen konnten, wurde diejenige gewählt, welehe Ellenberger und $\mathrm{H}$ ofmeister bei ihren zahlreichen, für die Ernährungsphysiologie der Haussäugethiere so werthvollen und bedeutenden Untersucbungen angewendet haben. Es ist das die Methode, welche zuerst $\mathrm{Schmidt}-\mathrm{Müheim}^{1}$ ) beim Hunde angewendet hat. Sie wurde jedoch erst von Ellenberger und $\mathrm{H}$ of meister weiter ausgebildet und systematisch durchgeführt. Nach derselben füttert man die Thiere (Pflanzenfresser) einige Tage hindurch gleichmässig mit dernselben Futter; hierauf lässt man sie 24-36 Stunden hungern, damit der Verdauungstrakt - soweit es beim Pflanzenfresser überhaupt möglich ist - von dem Vorfutter befreit werde. Dann wird erst das zu dem Versuche bestimmmte analysirte Futter in genau abgewogener Menge dem Thiere vorgelegt. Dem Zwecke des Versuches entsprechend wird alsdann das Thier eine gewisse Zeit nach der Nahrungsaufnahme getödtet, die einzelnen Abtheilungen des Magen-Darmkanales abgebunden und der Inhalt analysirt. Diese Methode bietet den gewiss nicht unwesentlichen Vortheil, ohne jeden operativen Eingriff genaue Aufklärung erhalten zu können über die qualitativen und quantitativen Verbältnisse der einzehnen Verdauungsvorgänge in den verschiedenen Abtheilungen des Magen-Darmtraktes. -- Ich war in der angenehmen Lage, mit den Details der Methode durch Herrn Medizinalrath E1le n berger selbst bekannt zu werden.

$\mathrm{Zu}$ meinen Versuchen wurden ausschliesslich gesunde Pferde gewählt resp. weiterhin nur diejenigen verarbeitet die sich auch bei der Section als gesund erwiesen. Im Ganzen batte ich 10 Pferde zur Verfügung, von denen jedoch 2 ausgeschlossen werden mussten, das eine, weil es an einem sehr heftigen Magenkatarrh litt, das andere, weil ein grober Versuchsfehler begangen wurde, der die analytisehen Daten unbrauchbar machte.

Die Thiere wurden 5 Tage nur mit Heu vorgefütert; 36 Stunden vor dem Versuche wurde ihnen jedes Futter entzogen, nur Trinkwasser wurde ihnen einige Male - das letzte 12 Stunden vor der Verabreichung des Ver-

1) Schmiả-Mülheim, Untersuchungen über die Verdauung der Eiweisskörper. (D a B o i s' Archiv 1879, pag. 39). 
suchsfutters - vorgesetzt. Dieses lange Hungern erwies sich als nothwendig, um den Magen und Dünndarm frei von Heuüberresten zu erhalten. - Nach dem 36 stündigem Hungern erhielten die Thiere genau abgewogene $1500 \mathrm{gr}$ eines analysirten Hafers. Die Menge des Hafers wurde deshalb relativ so klein bemessen, damit er, wie das auch bei allen Pferden der Fall war, vollständig verzehrt werde. Es waren auch Vorkehrungen getroffen, damit beim Fressen vom Futter nichts verloren gehe, so dass die Thiere thatsächlich alles bis auf das letzte Korn aufgenommen haben. Die Zeit, welche das Thier zum Verzehren des Futters brauchte, wurde auch notirt. Nach beendeter Mahlzeit blieben 3 Pferde ruhig im Stalle stehen, 3 wurden in Trab und 2 in Schritt getrieben. Die Ruhe resp. die Bewegung dauerte in jedem Versuche 1 Stunde vom Ende der Mahlzeit an gerechnet. Genau 1 Stunde nach beendeter Mahlzeit wurden die Thiere - im Institute selbst - getödtet. Dieser Zeitpunkt wurde deshalb gewählt, weil zu dieser Zeit die Verdauung bereits in vollem Gange ist und anderseits vom Versuchsfutter noch gar nichts in den Dickdarm gelangt, wovon ich mich übrigens bei jedem Pferde durch Oeffnen des Dickdarmes selbst überzeugte.

Nachdem das Thier verblutet war, wurde die Bauchhöble so rasch als möglich geöffnet, und vor allem der Magen am Pylorus und etwa $2 \mathrm{~cm}$ oberhalb der Cardia und das untere Ende des Ileum abgebunden; dann wurden Magen und Dünndarm rasch herausgeschnitten und auf $1-11 / 2$ Stunden in eine Kältemischung (Eis und Kochsalz) gelegt. Durch die starke Abkühlung wurde eine weitere Einwirkung der Verdauungsfermente verhindert. Nachher wurde der Magen- und Darminhalt entleert - (die auf der Schleimhaut klebenden Theile mit dem Finger sorgfältig abgestreift) - und gewogen.

Die Verarbeitung des Mageninhaltes geschah in folgender Weise: Nachdem derselbe zum Zwecke der gleichmässigen Vermischung gründlich durchgerührt war, wurde die Reaction mit Lakmus-, eventuell mit Tropaeolinpapier geprüft und 2 aliquote Theile zur Bestimmung der Trockensubstanz abgewogen. - 2 andere genau abgewogene aliquote Theile (70-80 gr) wurden auf je ein abgewogenes Filter gebracht, zwischen Eis gestellt, in hohe Glascylinder filtrirt und mit gekühltem destillirtem Wasser tagelang so lange gewaschen, bis das Filtrat auf Platinblech keinen Rückstand mehr gab. (In Eis gestellt und mit gekühltem Wasser wurde ebenfalls deshalb gewaschen, um eine weitere Einwirkung der vorhandenen Verdauungsfermente zu verhindern.) Der Filterrückstand wurde dann getrocknet und gewogen. Auf diese Weise wurde festgestellt, wie viel vom Mageninhalte in gelöstem und ungelöstem Zustande vorhanden war. - Das Filtrat, welches also die gelösten Substanzen des Mageninhaltes enthält, wurde in 2 Versuchen eingeengt, und darin die Menge der Kohlehydrate bestimmt. $Z u$ diesem $Z$ wecke wurden vom eingeengten Filtrate 2 aliquote Theile zur vollständigen Saccharificirung der gelösten Kohlehydrate mit $3 \%$ iger Schwefelsäure gekocht und in ihnen nach Entfernung der Eiweisskörper der Zucker nach der Allihn'schen Methode bestimmt. 
Ueber den Einfluss der Körperbewegung auf die Magenverdauung. 553

Im Gesammt-Mageninhalte wurden weiterhin stets mit Doppelanalysen in allen Versuchen die Rohfaser, in zwei Versuchen auch die Kohlehydrate-(Stärke+gelöste Kohlehydrate) quantitativ ermittelt. Die Rohfaserbestimmung geschah mittelst der bekannten Schwefelsäure-Kalilaugemethode ${ }^{1}$ ). Die Kohlehydrate wurden nach vollständiger Saccharificirung mit $3 \%$ iger Schwefelsäure und nach Entfernung der Eiweisskörper ebenfalls mit der Allihn'schen Methode bestimmt. Da auf diese Weise einerseits die Menge der gesammten, gelösten + ungelösten, Kohlehydrate festgestellt wurde nnd anderseits, wie oben angegeben, auch die Menge der gelösten Kohlehydrate constatirt wurde, konnte berechnet werden, wie viel Kohlehydrate noch u ngelöst blieben.

An dieser Stelle sei auch erwähnt, dass äussere Verhältnisse und ein unglücklicher Zufall es leider unmöglich machten, ausser den erwähnten 2 Versuchen auch in den übrigen die Kohlehydratverdauung quantitativ zu bestimmen. Aehnlich erging es mir auch mit den N-Bestimmungen des Mageninhaltes und mit den Analysen des Dünndarminhaltes.

Die 8 Versuche in der beschriebenen Weise bearbeitet, lieferten folgende Daten:

Der in allen Versuchen verwendete $\mathrm{Haf}$ er enthielt:

$$
\begin{array}{ll}
\text { Trockensubstanz } & 85,86 \% \\
\text { Wasser } & 14,14 \%
\end{array}
$$

Von der Trockensubstanz waren:

$\begin{array}{lr}\text { Rohfaser (aschefrei) } & 13,71 \% \\ \text { N-haltige Substanzen }(\mathrm{N} \times 6,25) & 12,23 " \\ \text { Kohlehydrate (als Dextrose gerechnet) } & 58,02 " \\ \text { Asche } & 3,39 " \\ \text { Näher nicht bestimmte organ. Substanzen } & 12,65 "\end{array}$

In jedem Versuche verzehrte das Pferd $1500 \mathrm{gr}$ dieses Hafers. Jedes Pferd nahm also mit diesem Futter auf:

$$
\begin{array}{lc}
\text { Trockensubstanz } & 1283,4 \mathrm{gr} \\
\text { Wasser } & 216,6
\end{array}
$$

In der aufgenommenen Trockensubstanz waren von den bei diesen Versuchen in Betracht kommenden Stoffen:

$$
\begin{array}{ll}
\text { Rohfaser } & 176,0 \mathrm{gr} \\
\text { Kohlehydrate } & 744,6
\end{array}
$$

1) Genau nach den Angaben von Ellenberger und Hofmeister, Ueber die Verdauung der Kartoffelstärke resp. der Kartoffeln bei Schweinen. Deutsche Zeitschr. f. Thiermedic. u. vergleich. Pathol. Bd. XIV. p. 320. 


\section{Versuch $\mathrm{I}$.}

Das Pferd hat $1500 \mathrm{gr}$ Hafer in 17 Minuten verzehrt. 1 Stunde lang nach beendeter Mahlzeit stand es ruhig im Stalle und wurde dann getödtet.

a) Mageninhalt $2921 \mathrm{gr}$.

$$
\begin{aligned}
& \text { Trockensubstanz } 770,4 \mathrm{gr}=26,36 \% \\
& \text { Wasser } \quad 2150,6 \%=73,64 \%
\end{aligned}
$$

Von der Trockensubstanz waren:

$$
\begin{aligned}
& \text { gelöst } 124,8 \mathrm{gr} \\
& \text { ungelöst } 645,6 \text { " }
\end{aligned}
$$

In der Trockensubstanz waren:

Rohfaser $93,66 \mathrm{gr}$.

b) Dünndarminhalt $6191 \mathrm{gr}$.

$$
\begin{aligned}
& \text { Trockensubstanz } 364,8 \mathrm{gr}=5,89 \% \\
& \text { Wasser } \quad 5826,2 "=94,11 \%
\end{aligned}
$$

\section{$\mathrm{Versuch}$ II.}

Das Pferd hat $1500 \mathrm{gr}$ Hafer in 20 Minuten gefressen. 1 Stunde lang nach beendeter Mahlzeit stand es ruhig im Stalle und wurde dann getödtet.

a) Mageninhalt $2566 \mathrm{gr}$.

$$
\begin{aligned}
& \text { Trockensubstanz } 859,6 \mathrm{gr}=33,5 \% \\
& \text { Wasser } 1706,4 \%=66,5 \%
\end{aligned}
$$

Von der Trockensubstanz sind:

$$
\begin{aligned}
& \text { gelöst } 156,1 \mathrm{gr} \\
& \text { ungelöst } 703,5,
\end{aligned}
$$

In der Trockensubstanz waren:

Rohfaser (aschefrei) 102,0.

$$
\begin{aligned}
& \text { Kohlehydrate }\left\{\begin{array}{l}
\text { gelöst } 65,6 \mathrm{gr} \\
\text { ungelöst } 413,0
\end{array}\right. \\
& \text { b) Dünndar minhalt } 5630 \mathrm{gr} . \\
& \text { Trockensubstanz } 385,8 \mathrm{gr}=6,85 \% \\
& \text { Wasser } 5244,2 \%=93,25 \% \\
& \text { V e r s u c h III. }
\end{aligned}
$$

Das Pferd hat die 1500 gr Hafer in 20 Minuten verzehrt. Sofort nach beendeter Mahlzeit wurde es 1 Stunde lang an der Longe im Trab getrieben und dann getödtet.

a) Mageninhalt $4005 \mathrm{gr}$.

$$
\begin{array}{ll}
\text { Trockensubstanz } 1290 \mathrm{gr} & =32,2 \% \\
\text { Wasser } & 2715 \%=67,8 \%
\end{array}
$$


Ueber den Einfluss der Körperbewegung auf die Magenverdaunng. 555

Von der Trockensubstanz waren:

$$
\begin{aligned}
& \text { gelöst } 399,1 \mathrm{gr} \\
& \text { ungelöst } 890,9,
\end{aligned}
$$

In der Trockensubstanz waren:

Rohfaser $146,8 \mathrm{gr}$.

Kohlehydrate $\left\{\begin{array}{l}\text { gelöst } 172,8 \mathrm{gr} \\ \text { ungelöst } 486,4,\end{array}\right.$

b) Dünndarminhalt $2975 \mathrm{gr}$.

$$
\begin{array}{ll}
\text { Trockensubstanz } & 134,0 \mathrm{gr}= \\
\text { Wasser } & 2841,0 "=
\end{array}
$$

\section{Versuch IV.}

Das Pferd hat die $1500 \mathrm{gr}$ Hafer in 22 Minuten verzehrt. Sofort nach beendeter Mahlzeit wurde es 1 Stunde lang an der Longe im Trab getrieben und dann getödtet.

a) Mageninhalt $4604 \mathrm{gr}$.

$$
\begin{array}{ll}
\text { Trockensubstanz } & 1221,4 \mathrm{gr}=26,5 \% \\
\text { Wasser } & 3382,6,=73,5 \%
\end{array}
$$

Von der Trockensubstanz sind:

$$
\begin{aligned}
& \text { gelöst } 233,1 \mathrm{gr} \\
& \text { ungelöst } 988,3 " \\
& \text { Rohfaser } 160,4 "
\end{aligned}
$$

b) Dünndarminhalt $5553 \mathrm{gr}$.

$$
\begin{aligned}
& \text { Trockensubstanz } 189,5 \mathrm{gr}=3,4 \% \\
& \text { Wasser } \quad 5363,5 \%=96,6 \%
\end{aligned}
$$

\section{Versuch V.}

Das Pferd hat die $1500 \mathrm{gr}$ Hafer in 17 Minuten verzehrt. Sofort nach beendeter Mahlzeit wurde es 1 Stunde an der Longe in Trab getrieben und dann getöltet.

a) Mageninhalt $4320 \mathrm{gr}$.

$$
\begin{aligned}
& \text { Trockensubstanz } 971,6 \mathrm{gr}=22,5 \% \\
& \text { Wasser } \quad 3448,4,=77,5 \text {, } \\
& \text { Rohfaser } 132,9 \mathrm{gr} \text {. } \\
& \text { b) Dünndarminhalt } 5158 \mathrm{gr} \text {. } \\
& \text { Trockensubstanz } \quad 298,6 \mathrm{gr}=5,8 \% \\
& \text { Wasser } \quad 4859,4 n=94,2,
\end{aligned}
$$




\section{Versuch VI.}

Das Pferd hat die $1500 \mathrm{gr}$ Hafer in 24 Minuten verzehrt. 1 Stunde lang nach beendeter Mahlzeit stand es ruhig im Stall und wurde dann sofort getödtet.

a) Mageninhalt $3356 \mathrm{gr}$.

$$
\begin{aligned}
& \text { Trockensubstanz } 999,8 \mathrm{gr}=29,8 \% \\
& \text { Wasser } \quad 2356,2,=70,2 \text {, } \\
& \text { Rohfaser 100,9 gr. } \\
& \text { Trockensubstanz } 279,5 \mathrm{gr}=4,5 \% \\
& \text { Wasser } \quad 5878,5,=95,5 \text {, }
\end{aligned}
$$

\section{Versuch VII.}

Das Pferd verzehrte die $1500 \mathrm{gr}$ Hafer in 29 Minuten. Sofort nach beendeter Mahlzeit wurde es 1 Stunde lang im Schritt geführt und dann getödtet.

a) Mageninhalt $3674 \mathrm{gr}$.

$$
\begin{aligned}
& \text { Trockensubstanz } 968,5 \mathrm{gr}=26,4 \% \\
& 2705,5,=73,6, \\
& \text { Wasser } \begin{array}{r}
\% \\
\text { Rohfaser } 109,4 \mathrm{gr} .
\end{array} \\
& \text { b) Dünndarmin halt } 8988 \mathrm{gr} . \\
& \text { Trockensubstanz } 326,3 \mathrm{gr}=3,6 \% \\
& \text { Wasser } \quad 8661,7,=96,4, \\
& \text { V e r s u c h VIII. }
\end{aligned}
$$

\section{Versuch VIII.}

Das Pferd hat die $1500 \mathrm{gr}$ Hafer in 16 Minuten verzehrt. Sofort nach beendeter Mahlzeit wurde es 1 Stunde lang im Schritt geführt und dann getödtet.

$$
\text { a) Mageninhalt } 3460 \mathrm{gr} \text {. }
$$

$$
\begin{aligned}
& \text { Trockensubstanz } 1033,5 \mathrm{gr}=29,9 \% \\
& 2426,5 \%=70,1 \% \\
& \text { Wasser Rohfaser } 140,9 \mathrm{gr} . \\
& \text { b) Dünndarminhalt } 5550 \mathrm{gr} . \\
& \text { Trockensubstanz } 329,2 \mathrm{gr}=5,9 \% \\
& \text { Wasser } 5220,8,=94,1,
\end{aligned}
$$

Wenn ich auch bei der geringen Zahl meiner Versuche und mit Rücksicht anf ibre Unvollständigkeit weit entfernt davon bin zu glauben, die aufgeworfene Frage gelöst zu haben, so sind doch 
Ueber den Einfluss der Körperbewegung auf die Magenverdauung. 557 einige geuügend sichere Resultate dieser Versuche in mancher Beziehung interessant und werth mitgetheilt zu werden, um so mehr, da diese Versuche, wie bereits erwähnt, die ersten sind, die an Pferden angestellt wurden.

III.

Die auffallendste Beeinflussung durch die Körperbewegungen zeigten die mechanischen Vorgänge im Magen, speciell die Weiterbeförderung der Ingesta in den Dünndarm, also die Motilität des M a gens. A priori ist es nicht unwahrscheinlich, dass die Bewegung des Mageninhaltes durch die Erschütterungen, welche der ganze Körper bei der Locomotion, besonders bei der lebhafteren wie z. B. beim Trabe, erleidet, ebenfalls beeinflusst wird. Unsere Versuche eigneten sich insofern sebr gut zur Beantwortung dieser Frage, als im Futter ein Bestandtheil - die Rohfaser - durch ibre absolute Unverdaulichkeit im Magensafte und Speichel (E l lenberger und Hofme ister) in sehr zuverlässlicher Weise dazu benutzt werden konnte, zu bestimmen, wieviel von dem aufgenommenen Futter bereits in den Darm ïbergetreten ist. Was von der aufgenommenen Rohfaser, deren Menge im Versuchsfutter durch directe Analysen genau bekannt ist, im Magen fehlt, das ist zweifellos in den Dünndarm weiterbefördert worden. Die Sicherheit der Resultate wird nicht wenig dadurch erhöht, dass bei unseren Versuchen der Magen den Leichen entnommen und vollständig entleert wird, von seinem Inhalte sicher nichts zurückbleiben kann, wovon man sich bei Versuchen, wo der Mageninhalt dureh Aushebern gewonnen wird, doch nicht sicher überzeugen kann.

Da die Rohfaser im Mageninhalte ziemlich gleichmässig vertheilt ist und der Mageninhalt annähernd gleichmässig in den Dïnndarm vorgeschoben wird, wie das in einem späteren Kapitel bewiesen wird, so kann man aus der Rohfasermenge auch auf die in den Darm beförderte Hafermenge folgern.

Die folgende Tabelle I enthält die Rohfaserbefunde der einzelnen Versuche.

Aus diesen Zahlen geht es unzweifelhaft hervor, dass im Magen der bewegten Pferde ausnahmlos mehr Rohfaser, also auch mehr Hafer vorhanden ist als bei den ruhenden, mithin weniger in den Darm befördert wurde. Wir gelangten somit zu dem ganz uner- 


\section{Tabelle I.}

Aufgenommen wurden in jedem Versuche 176,0 gr Rohfaser.

\begin{tabular}{|c|c|c|c|c|c|c|}
\hline \multirow{2}{*}{ 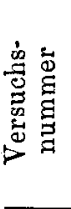 } & \multirow{2}{*}{ 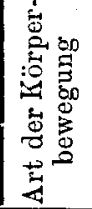 } & \multirow{2}{*}{\multicolumn{2}{|c|}{$\begin{array}{l}\text { Rohfaser im } \\
\text { Magen } \\
\begin{array}{l}\text { von der auf- } \\
\text { genommenen } \\
\text { Rohfaser \% }\end{array} \\
\end{array}$}} & \multicolumn{3}{|c|}{$\begin{array}{c}\text { Von der aufgenommenen } \\
\text { Rohfaser gelangten also } \\
\text { in den Darm }\end{array}$} \\
\hline & & & & $\mathrm{gr}$ & $\%$ & $\begin{array}{l}\text { ch- } \\
\text { tlich }\end{array}$ \\
\hline $\begin{array}{l}\text { I. } \\
\text { II. } \\
\text { VI. }\end{array}$ & $\begin{array}{l}\text { Zuhe } \\
" \\
"\end{array}$ & $\begin{array}{r}93,7 \\
102,0 \\
100,9\end{array}$ & & $\begin{array}{l}82,3 \\
74,0 \\
75,1\end{array}$ & & $43,8 \%$ \\
\hline $\begin{array}{l}\text { III. } \\
\text { IV. } \\
\text { V. }\end{array}$ & $\begin{array}{c}\text { Trab } \\
" \\
"\end{array}$ & $\begin{array}{l}146,8 \\
160,4 \\
132,9\end{array}$ & $\begin{array}{l}84,0 \\
91,1 \\
75,5\end{array}$ & $\begin{array}{l}30,2 \\
15,6 \\
33,1\end{array}$ & $\begin{array}{r}16,0 \\
8,9 \\
24,5\end{array}$ & 16,5 \\
\hline VII. & $\left.\right|_{n} ^{\text {Schritt }}$ & $\begin{array}{l}109,4 \\
140,9\end{array}$ & $\begin{array}{l}62,2 \\
80,1\end{array}$ & $\begin{array}{l}66,6 \\
35,1\end{array}$ & $\begin{array}{l}37,8 \\
19,9\end{array}$ & 28,9 \\
\hline
\end{tabular}

warteten Resultate, dass beim Pferde die Körperbewegungen die Entleerung des Magens in nicht unerheblichem Maasseverlangsamen, was ganz besonders beider intensiveren Bewegung, beim Trabe in tiberzeugender Weise ersicbtlich ist. Während bei voller Ruhe nach der Futteraufnahme in 1 Stunde durchschnittlich $43,8 \%$ des aufgenommenen Hafers, sind in derselben Zeit bei Bewegung in Schritt nur $28,9 \%$, bei Trab sogar nur 16,5\% in den Dünndarm geschafft worden. In letzterem Falle ist also weniger als die Hälfte der bei Ruhe weiterbeförderten Hafermenge in den Darm gelangt. Da bei Trab auch bedeutend weniger als bei der Bewegung in Schritt ans dem Magen in den Darm befördert wurde, ist es auch wahrscheinlich, dass die Verzögerung der Magenentleerung mit der Intensität der Körperbewegungen wächst.

Unsere Versuche stimmen auf diese Weise durchaus nicht mit den Angaben Colin's ${ }^{1}$ ) überein. C. behauptet, dass beim Pferde die Körperbewegungen die Weiterbeförderung des Mageninhaltes zu beschleunigen scheinen und führt als Beispiel an, dass er bei einem Pferde, welches 6 Stunden lang Bewegung machte, im Magen 3500 gr Chymus fand, also um $743 \mathrm{gr}$ weniger als im

1) Colin, Traité de physiologie comparée des animaux. Paris 1886. Bd. I. p. 822 . 
Ueber den Einfluss der Körperbewegung auf die Magenverdaunng. 559

Magen eines anderen Pferdes, das nach einer ähnlichen Mahlzeit - 2500 gr Hafer - 6 Stunden in Ruhe gelassen wurde. Leider giebt C. nicht an, welcher Art die vom Pferde ausgeführten Körperbewegungen waren; ausserdem scheint er nur ein einziges Pferd untersucht zu haben.

Beim Hunde untersuchte Salvioli, beim Menschen Spirig die Veränderung der Motilität des Magens. Salvioli fand bei einem kleinen Hunde, in dem durch Apornorphin erbrochenen Mageninhalte viel weniger unverdaute Eiweissstücke, wenn er ihn 3 Stunden laufen, als wenn er ibn ebenso lange in Rube liess. Einen Versuch mit ähnlichem Resultate hat er auch an einem Magenfistelhunde mit Milch angestellt. Auch fand er bei einem Hunde, den er nach 2 stündigem Laufe tödtete, von den Eiweissstücken nur noch sehr wenig im Magen, die meisten waren unverdaut im Ilenm. Mit diesen - eigentlich nur 2 Versuchen sieht es S. bewiesen, dass die aufgenommene Nahrung, wenn auch unverdaut, vom Magen schneller in den Darm gelange bei jenen Thicren die laufen, als bei jenen, die ruhen. Er hält es auch für wahrscheinlich, dass dies durch gesteigerte Bewegungen der Magenmuskulatur geschieht.

S pirig ${ }^{2}$ ) hat beim Menschen mit der Ewald-Sievers'schen Salolmethode die Motilität des Magens geprüft und gefunden, dass die Salicylsüure im Harn umso früher erscheint, je intensiver die Körperbewegung war, dass also dementsprechend, das Salol früher in den Darm gelangt ist. Sp. folgert daraus, dass die Motilität des Magens während der Körperbewegungen gesteigert ist. Dafür spreche auch der Umstand, dass erwiesenermaassen die Resorption bei Bewegung unverändert, die Menge der Umsetzungsprodukte des Eiweisses geringer ist, letztere also rascher in den Darm abgeführt werden als bei Ruhe. (Freilich muss bemerkt werden, dass die Saloimethode bekanntlich nichts weniger als einwandsfrei ist.)

Mehr Versuche wurden meines Wissens diesbeziiglich nicht angestellt. Wenn auch die angeführten einer Ergänzung bedürfen, so scheinen sie doch dafür zu sprechen, dass beim Menschen und Hunde gerade das Gegentheil dessen besteht, was wir beim Pferde beobachtet haben. Es scbeint also, dass die Motilität des Magens

1) Salvioli, l. c.

2) Spirig, l. c. 
während der Körperbewegungen bei einer Thierart gesteigert, bei der anderen verringert wird.

Unsere Befunde beim Pferde sind umso auffallender, als gerade die anatomische Einrichtung des Pferdemagens zu einer schnelleren Beförderung des Inhaltes bei Körperbewegungen, durch welche ja anch der Mageninhalt kräftig geschüttelt wird, ganz besonders geeignet schien. Der Pylorus ist nämlich absolut und relativ viel weiter, der Schliessmuskel schlaffer als z. B. beim Hundemagen. Colin sagt an der oben angefuthrten Stelle seines Buches wörtlich das folgende: „Il est évident, d'après la rapidité arec laquelle les aliments et les liquides parviennent à l'intestin, que le pylore des solipèdes doit fonctionner suivant un mode particulier, qui ne lui appartient point dans la plupart des animaux. Cet orifice est effectivement très dilatable, large et presque toujours béant, comme on s'en assure aisément sur les animaux vivants, dont l'estomac est plein et la digestion active. Il est par conséquent, chez le cheval, bien différent de ce qu'il est chez les carnassiers." Und doch gelangt der Mageninhalt bei einer lebhafteren Körperbewegung, wo man erwarten könnte, dass die Erschütterungen die Entleerung des Magens befördern sollten, langsamer in den Dïnndarm! Unter solchen Verhältnissen müssen wir unbedingt annehmen, dass durch die Körperbewegungen auf irgend eine Art, die Entleerung des Magens verhindert, resp. verlangsamt wird. Das nächstliegende ist, an eine reflectorische Hemmung der Magenbewegungen oder eine reflectorische Schliessung oder Verengung des Pylorus zu denken. Dass die Magencontractionen auf reflectorischem Wege gehemmt werden können, ist eine bekaunte Thatsache. Wertheimer ${ }^{1}$ ) konnte beim Hunde durch Reizung des centralen Ischiadicusendes die Contractionen der Magenmusculatur hemmen. Aehnliche Wirkung hat die Reizung eines centralen Vagusstumpfes. Uebrigens fand schon 0 penchows $\mathrm{Ki}^{2}$ ), dass die Contraction des Cardia- sphincters von den verschiedensten sensiblen Nerven des Körpers auf reflectorischem Wege gehemmt werden kann.

1) Wertheimer, Inhibition réflexe du tonus et des mouvements de l'estomac. (Arch. de physiologie norm. et pathol. 1892. p. 379.)

2) Opench owski, Ueber Centren und Leitungsbahnen für die Musculatur des Magens. Du Bois' Archiv. 1889. p. 549. 
Ueber den Einfluss der Körperbewegung auf die Magenverdaung. 561

Auch Mering ${ }^{1}$ ) giebt an, dass er sich mehrfach davon überzengte, dass die psychische Erregung die Entleerung des Magens hemmt, ebenso verlangsame auch die Anfüllung des Dünndarmes reflectorisch die Entleerung des Magens.

In einer an Katzen noch nicht lange begonnenen Versuchsreihe habe ich mich auch davon überzeugen können, dass durch die Reizung des centralen Ischiadicusstumpfes sowohl die Bewegungen des Pylorus als auch des Darmes auf reflectorischem Wege beeinflusst werden können, worüber ich in einer späteren Mittheilung: ausführlich berichten werde. Es wäre also möglich, dass auch beim Pferde die Contractionen der Magenmuskulatur während der Körperbewegungen auf reflectorischem Wege gehemmt werden oder der Pylorus vielleicht stärker contrahirt ist; das müsste aber erst experimentell geprüft werden.

Bei dieser Gelegenheit möchte ich auch mit einigen Worten die Angabe über den Zeitpunkt des Uebertrittes der Magencontenta in den Dünndarm, besprechen. Ellenberger ${ }^{2}$ ) sagt in seinem Handbuche: „Bei kleinen und kurzdauernden Hafermahlzeiten beginnt der Uebertritt dos Mageninhaltes nach dem Darm erst 2-3 Stunden nach der Mablzeit". Dagegen ist Gol dschmidt ${ }^{3}$ ) der Meinung, dass ein Theil des Futters schon während des Fressens in den Dünndarm übergeht. Dasselbe giebt auch Colin ${ }^{4}$ ) an.

Bei meinen Versuchen fand ich sowohl bei den ruhenden als bei den laufenden Pferden 1 Stunde nach der Mahlzeit, einen Theil des aufgenommenen Hafers bereits im Diunndarm. Ausser diesen Versuchen habe ich noch ein Pferd unter äbnlichen Versuchsbedingungen wie bei den acht Versuchen 10 Minuten, nachdem es $1500 \mathrm{gr}$ Hafer verzehrte, getödtet und im Dünndarm bereits Hafer gefunden. Nach meinen Erfahrungen schliesse ich mich also der Ansicht Goldschmidt's und Colin's an, dass beim Pferdesehon während der Futteraufnahme

1) Mering, Ueber die Function des Magens. Verhandl. des XII. Congresses für innere Medicin zu Wiesbaden. 1893.

2) Ellenberger, Vergleich. Physiologie der Haussäugethiere. 1890.

I. Theil. p. 756 .

3) Goldschmidt, Die Magenverdaung des Pferdes. Zeitschr. f. physiol. Chemie. Bd. X. p. 389.

4) Colin, loc. cit. p. 820 . 
der Mageninhalt in den Dünndarm ỉberzutreten beginnt.

Schliesslich möchte ich noch kurz die Frage berühren, ob durch die Körperbewegungen die Durchmischung des Inhaltes im Magen selbst befördert wird. Goldschmidt ${ }^{1}$ ) und Ellenberger ${ }^{2}$ ) fanden, dass beim Pferde der Mageninhalt keine rotirende Bewegungen macht, dass keine Durchmischung verschiedener nach einander genossener Nabrungsmittel stattfindet, sondern dass „sich die in den Magen eintretenden Massen von der Cardia aus fächerartig nach allen Richtungen hin verschieben." Ausserdem haben sowohl Ellenberger als auch Golds chmidt bewiesen, dass beim Pferde (und Schweine) in dem Mageninhalte „ein scharfer Unterschied zwischen dem Inhalte der Schlund- und dem der Pylorusbälfte des Magens noch Standen lang besteht ${ }^{3}$ ), was natürlich nur so möglich ist, dass der Mageninhalt durch die Magenbewegungen nicht durchmischt wird. Bei meiner Versuchsanordnung hätte ich uiber diese Verbältnisse nur so Aufschluss erhalten können, wenn ich die Schlund- und Pylorushälfte des Magens gesondert untersucht bätte. Die Grenze zwischen beiden Magenabtheilungen ist schon äusserlich durch eine Furche angedeutet. Ich habe bei einem ruhenden Pferde (Vers.I.) und bei einem, welches 1Stunde lang nach der Futteraufnahme trabte, wie in den Versuchen IV-VI, vor der Eröffnung des Magens denselben an der erwähnten Grenze abgebunden und so den Inbalt der Pylorushälfte von dem der Schlundhälfte getrennt und weiter auch getrennt untersucht. (Das letztere Pferd, welches trabte ist unter den Versuchen, nicht eingereiht, weil es den Hafer (1500 gr) nicht vollständig gefressen hat, sondern nur $1416 \mathrm{gr}$ und dazu 45 Minuten branchte. Es hatte schlechte Zäbne. Ansserdem hatte es einen Magenkatarrh. Der Mageninhalt wurde auch nur zu dem Zwecke untersucht, ob ein Unterschied zwischen der Pylorus- und der Schlundabtheilung vorhanden ist.)

Bei der Beurtheilung der Befunde diurfen wir aber nicht vergessen, dass bei einem nur etwas flüssigeren Mageninhalte, beim Tödten des Thieres, bei der Herausnahme und dem Abbinden des

1) Goldschmidt, 1. c. p. 384 .

2) Ellenberger, l. c. Bd. I. p. 732.

3) Ellenberger, Handbuch I. Bd. p. 825. 
Magens von der einen Abtheilung sehr leicht ein Theil in die andere überfliessen und so die Unterschiede verdecken kann. Ausserdem ist am Anfange der Magenverdauung, wo wie Ellenberger und Hofmeister nachgewiesen haben im ganzen Magen Stärke verdaut wird, der Unterschied zwischen den zwei Abtheilungen nicht bedeutend. Die geringen quantitativen Unterschiede, die ich im Wassergehalt und in den Verdauungrsproducten zwischen der Schlund- und Pylorusabtheilung des Magens fand, sind so unbedeutend, dass ich auf sie weiter gar nicht eingehen will. Nur eines möchte ich hervorheben. Bei dem ruhenden Pferde reagirte der gut durchmischte Inhalt der Pylorushälfte filtrirt und unfiltrirt sehr dentlich sauer, während der der Schlundhälfte dentlich alkalisch reagirte. Derselbe Unterschied bestand auch bei dem Pferde, welches trabte. Zieht man ferner in Betracht, dass, wie es das folgende Kapitel zeigen wird, der Mageninhalt während der Körperbewegung wasserreicher, flüssiger wird, also eine Durehmischung des Mageninhalts eeteris paribus leichter stattfinden kann, so spricht der bedeutende Unterschied in der Reaction dafür, dass während der Körperbewegung eine Durchmischung des Mageninhaltes ebenso wenig stattfindet, wie bei der Ruhe.

IV.

Ausser der Motilität des Magens, wird auch die secretorische Thätigkeit seiner Sehleimhaut während der Körperbewegungen modificirt. Meine diesbeziiglichen Beobachtungen erstrecken sich aber nicht auf den ganzen Umfang der Magensecretion, sondern nur auf die Secretion des Wassers.

a) Zur Beurtheilung der Wassersecretion im Magen konnte ich nur die Wassermenge des Mageninhaltes benitzen. Ein Untersehied im Wassergehalt des Mageninhaltes ruhender und bewegter Pferde zeigte sich in einigen Versuchen schon beim Durchruihren, indem der Mageninhalt der bewegten Pferde meist wässriger war. Die folgende Tabelle II giebt den ziffermässigen Ausweis iiber den Wassergehalt.

Nach diesen Zahlen enthält der Mageninhalt bei Körperbewegung, besonders bei der intensiveren, absolut und auch relativ mehr Wasser. Nehmen wir die 3 ruhenden und die 3 trabenden Pferde, so sind bei ersteren durchsehnittlich $2071 \mathrm{gr}=70,1 \%$, bei letzteren $3182 \mathrm{gr} .=72,9 \%$ Wasser in Mageninhalte. Die 2 
Tabelle II.

\begin{tabular}{|c|c|c|c|c|c|c|c|}
\hline \multirow{2}{*}{ 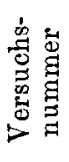 } & \multirow{2}{*}{ 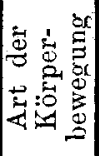 } & \multirow{2}{*}{ 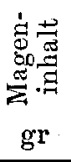 } & \multirow{2}{*}{ 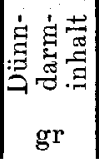 } & \multicolumn{2}{|c|}{$\begin{array}{l}\text { Wassergehalt } \\
\text { des Magen- } \\
\text { inhaltes }\end{array}$} & \multicolumn{2}{|c|}{$\begin{array}{l}\text { Wassergehalt } \\
\text { des Dünn- } \\
\text { darminhaltes }\end{array}$} \\
\hline & & & & $\mathrm{gr}$ & $\%$ & $\mathrm{gr}$ & $\%$ \\
\hline I. & Ruhe & 2921 & 6191 & 2151 & 73,6 & 5826 & 94,1 \\
\hline II. & & 2566 & 5630 & 1706 & 66,5 & 5244 & 93,3 \\
\hline VI. & 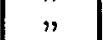 & 3356 & 6158 & 2356 & 70,2 & 5878 & 95,5 \\
\hline III. & Trab & 4005 & 2975 & 2715 & 67,8 & 2841 & 95,5 \\
\hline IV. & 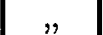 & 4604 & 5553 & 33 & 73 & 5363 & 96,6 \\
\hline & & 4320 & 5158 & 3448 & 77,5 & 4859 & 94,2 \\
\hline VI & Schritt & 3674 & 8988 & 270 & 73,6 & 8662 & 96,2 \\
\hline & & 3460 & 5550 & 2427 & 70,1 & 5221 & 94,1 \\
\hline
\end{tabular}

Pferde, welche im Schritt bewegt wurden, stehen mit $2566 \mathrm{gr}=$ $71,9 \%$ zwischen beiden.

Es ist unzweifelhaft, dass der allergrösste Theil des im Mageninhalte vorhandenen Wassers vom verschluckten Speichel stammt. Ellenberger ${ }^{1}$ ) giebt an, dass beim Pferde beim Kauen des Hafers der secernirte Speichel das doppelte Gewicht des verzehrten Hafers ausmacht. Nach Lassaigne ${ }^{2}$ ) beträgt der Speichel etwas mehr als das Gewicht des Hafers. Bei unseren Versuchen würden dem entsprechend die Pferde etwa 2000-3000 gr Speichel, also die geringe Trockensubstanz des Speichels abgerechnet, etwas weniger Wasser verschluckt haben; dazu kommt noch das im Hafer enthaltene Wasser (217 gr). Nun verschwindet aber sehr bald ein Theil dieses Wassers aus dem Magen, da ein Theil des Mageninhaltes noch während des Fressens in den Dänndarm befördert wird. (Auf einem anderen Wege als durch Hinüberfliessen in das Duodenum verschwindet kein Wasser ans dem Magen, da letzterer wie v. Mering ${ }^{3}$ ) zeigte - keine in Betracht kommende Menge Wassers resorbirt.) Wenn auf diese Weise die Wassermenge im Magen abnimmt, so wird sie anderseits 'durch die Wassersecretion der Magenschleimhaut vermehrt.

1) Ellenberger, 1. c. I. Bd. p. 511.

2) Lassaigne, Citirt nach Colin, l. c. T. I. p. 663.

3) v. Mering, Ueber die Function des Magens. (Verhandl. des XII. Kongresses f. innere Medicin in Wiesbaden. 1893. 
Unter solchen Verhältnissen ist natürlich die Deutung des Befundes einer grösseren Wassermenge im Mageninhalte nicht so einfach.

Wie es die Tabelle II unzweifelhaft beweist ist im Mageninhalte der bewegten Pferde nicht nur ausnahmslos mehr Wasser als in demjenigen der ruhenden, sondern es ist in zwei Versuchen (Nr. IV. und V.) mehr Wasser als nach unserer eben ausgefuhrten Berechnung verschluckt sein konnte. Denn selbst wenn wir mit Ellenberger annehmen, dass in jedem Falle $3000 \mathrm{gr}$ Speichel verschluckt werden, so gïbe das mit dem Wasser des Hafers höchstens etwa $3200 \mathrm{gr}$ Wasser, während in den Versuchen IV und V 3383 resp. $3448 \mathrm{gr}$ Wasser waren. Dies ist umso bemerkenswerther, als ja ein Theil des versehluckten Wassers bereits (mit dem übertretenen Mageninhalte) in den Dünndarm befördert wurde: Schon diese absolut grössere Wassermenge bei den bewegten Pferden, spricht entschieden für eine gesteigerte Wassersecretion der Magenschleimhaut während der Körperbewegung. Es wäre allerdings denkbar, dass bei den bewegten Pferden nur deshalb mehr Wasser im Magen ist, weil vom Mageninhalt überhaupt weniger in den Dünndarm gelangt, wie wir das ja auch thatsächlich oben bewiesen haben. Wäre das allein die Ursache des grösseren Wassergehaltes bei dem trabenden Pferde, so mlisste, eine gleichmässige Verschiebung des Mageninhaltes vorausgesetzt, der procentische Wassergehalt derselbe sein, wie bei den ruhenden Pferden. Findet hingegen keine gleichmässige Verschiebung des Mageninhaltes statt, so ist es doch wahrscheinlich, dass wenn schon die Entleerung des Magens während der Körperbewegungen erschwert, beziehentlich verlangsamt ist, dies in erster Reihe die festeren Bestandtheile des Mageninhaltes treffen wird, also vom flïssigen Theil desselben relativ mehr - (wenn auch absolut weniger) - in den Dünndarm gelangt. Dann muisste aber bei den bewegten Pferden mit verlangsamter Magenentleerung der Mageninhalt procentisch weniger Wasser enthalten. Thatsächlich ist: aber bei den trabenden Pferden nicht nur der absolute, sondern auch der procentische Wassergehalt des Mageninhaltes - wenn auch nicht bedeutend - so doch grösser als bei den ruhenden, was unter solchen Umständen nur so erklärlich ist, dass während des Trabens im Magen mehr Wasser secernirt würde. Wir gelangen somit zu dem Schlusse, dass die (intensiveren) K ö r per- 
bewegungen beim Pferde die Wassersecretion der Magenschleimbat steigern.

Ganz unerwartet kam mir dieses Resultat nicht, da Goldschmidt ${ }^{1}$ ) erwähnt, dass er den Mageninhalt des Pferdes verhältnissmässig trocken, ausnahmsweise aber sehr wasserreich gefunden hat, dass er aber bei keinem Pferde „die sich nicht bewegt hatten (die aber auch kürzere Zeit gehungert) einen flüssigen Mageninhalt vorfand." Er denkt an die Möglichkeit der Veränderung in der Resorptionsfähigkeit des Magens während der Körperbewegung, Auch Ellenberger ${ }^{2}$ ) giebt an, dass von 49 untersuchten Pferden der Inhalt des Magens bei 36 dickbreiig und wasserarm und nur bei 13 dünnbreiig und wasserreich war; „letzteres schien besonders der Fall zu sein, wenn die Thiere gleich nach der Mahlzeit bewegt wurden." Eine Erklärung dieses Befundes giebt Ellen berger nicht.

Bei dieser Gelegenbeit sei auch gleich erwähnt, dàss, wie auch Tabelle II zeigt, der Wassergehalt des Dünndarminhaltes ebenfalls bestimmt wurde. Doch sind die einzelnen Befunde bei den bewegten Pferden von einander so abweichend, dass diese Unterschiede grösser sind als diejenigen zwischen ruhenden und bewegten Pferden. Dazu kommt noch, dass die Verhältnisse beim Dünndarm viel complicirter sind, da zu den verschiedenen Secretionen auch die Resorption des Wassers kommt. Somit ist es also unmöglich, aus dem Wassergehalt irgendwelche Schlüsse zu ziehen, zumal es keine ausgesprochene Veränderung zeigt. Der procentische Wassergehalt scheint während der Körperbewegung etwas grösser zu sein.

2) Bei der Prüfung einer eventuellen Veränderung der Säureproduction im Magen während der Körperbewegung musste vor allem der Umstand berïcksichtigt werden, dass die Untersuchung in einem Stadium der Verdaung vorgenommen wurde, in welchem nach den Untersuchungen von El l en berger und $\mathrm{H}$ ofme is te $\mathrm{r}^{3}$ ) und auch Goldsehmidt $\mathrm{t}^{4}$ ) im Magen-

1) Goldschmidt, 1. c. pag. 374.

2) Ellenberger, sein Handbuch. Bd. I. p. 808.

3) Ellenberger und Hofmeister, Ueber die Verdaungssäfte und die Verdauung des Pferdes. III. Die Magenverdaung des Pferdes. (Arch. f. wissenschaftl. u. pract. Thierheilkunde. Bd. VIII. p. 395.)

4) Goldschmidt, l. c. 
Ueber den Einfluss der Körperbewegung auf die Magenverdauung. 567

inhalte des Pferdes noch keine freie Salzsäure vorhanden ist, sondern nur Milchsäure. E. u. H. konnten erst 3 Stunden nach dem Fressen Spuren von Salzsäure nachweisen. Diesen Angaben entsprechend habe ich in keinem einzigen Versuche, weder bei ruhenden noch bei bewegten Pferden im Mageninhalte freie $\mathrm{HCl}$ nachweisen können (Tropaeolin, Methylviolett). War der Mageninhalt sauer, so stammte die saure Reaction nachweisbar von Milchsäure (Carboleisenreaction). Der (gut durchmischte) Mageninhalt reagirte aber nicht in allen Versuchen sauer, wie das die folgende Zusammenstellung beweist.

\begin{tabular}{c|c|c}
\hline $\begin{array}{c}\text { Versuch- } \\
\text { nummer }\end{array}$ & $\begin{array}{c}\text { Art ber Körper- } \\
\text { bewegung }\end{array}$ & Reaction des Mageninhaltes \\
\hline I. & Ruhe & $\begin{array}{c}\text { In der Pylorus- In der Schleim- } \\
\text { hälfte sauer }\end{array}$ \\
II. & Ruhlfte alkalisch \\
VI. & Ruhe & sauer \\
III. & Trab & sauer \\
IV. & Trab & schwach alkalisch \\
V. & Trab & alkalisch \\
VII. & Schritt & sauer \\
VIII. & Schritt & sauer
\end{tabular}

Die Prifung geschah mit Lakmuspapier.

Es reagirtealso der Mageninhalt der ruhendeu und der in Schritt bewegten Pferde sauer, derjenige der trabenden Pferde alkaliseh. Wie bereits erwähnt, stammte die saure Reaction ron freier Milchsäure.

Die nächstliegende Erklärung dieses Befundes wäre die Annahme, dass durch die Körperbewegungen ebenso wie die Motilität der Magenmusculatur auch die Säureproduction der Schleimhaut herabgesetzt wird. Geben doch $\operatorname{Cohn}^{1}$ ) und Salviolia) für den Hund und Spi rig ${ }^{3}$ ) für den Menschen an, dass die Acidität des Mageninhaltes während der Körperbewegung abnimmt, was in ihren Versuchen nur durch verminderte Säureproduction erklärbar ist; nur Surmont und Brunelle ${ }^{4}$ ) behaupten das Gegentheil, d. h. dass die Acidität zunehme.

1) Cohn, 2) Salvioli, 3) Spirig, loc. cit.

4) Surmont und Brunelle, l. c. 
Wenn auch in unseren Versuchen die alkalische Reaction des Mageninhaltes bei den trabenden Pferden mit der Annahme einer verminderten Säureproduction wohl vereinbar wäre, so bildet dieselbe doch keinen Beweis dafür. Während des Trabens ist die Entleerung des Magens bedeutend verlangsamt, es werden also auch viel grössere Mengen des im verschluckten Speichel vorhandenen Alkalis im Magen zurückbleiben. Daraus folgt aber, dass selbst in dem Falle, dass die Magenschleimhant ebenso viel Säure producirt als bei den ruhenden Pferden, dieselbe ganz neutralisirt werden, ja noch übersehiissiges Alkali übrig bleiben kann. Unter solchen Verhältnissen wäre es sogar möglich, dass selbst dann, wenn mehr Salzsäure als bei ruhenden Pferden producirt wird, der Mageninhalt doch alkalisch reagiren könnte. Aus all dem geht hervor, dass wir aus unseren Befunden nicht entscheiden können, wie sich die Secretion der Säure während der Körperbewegung verändert. Wir können auch die oben nachgewiesene vermehrte Wassersecretion zur Entscheidung dieser Frage nicht heranziehen, da die Untersuchungen von v. Mering ${ }^{1}$ ) gezeigt haben, dass (beim Hunde) auch dann reichlich Wasser secernirt wird, wenn sich keine $\mathrm{HCl}$ nachweisen lässt.

V.

Die Unterschiede, die wir bisher in den Magenfunctionen der ruhenden und bewegten Pferden constatirt haben, namentlich die langsamere Entleerung des Inhaltes, die alkalische Reaction und der grössere Wassergehalt desselben bei den bewegten Pferden liessen vermuthen, dass bei letzteren auch die Ausgiebigkeit der Magenverdauung Unterschiede zeigen werde. Die Ermittelung dieser Unterschiede setzt aber vor allem eine zuverlässliche Bestimmung der Ausgiebigkeit der Magenverdaung voraus. Wie soll nun der Grad der Verdauung bestimmt werden? Wäre in jener Periode der Verdaung, wo der Mageninhalt untersucht wurde, noch nichts in den Darm ibergegangen, so wäre es ja sehr leicht festzustellen, wie viel von dem aufgenommenen Futter bereits verdaut resp. schon resorbirt ist. So aber darf man den Theil des Futters, welcher in den Darm übergegangen ist, nicht unberücksichtigt lassen. Es dürfte sich also kaum eine andere Methode

1) v. Mering, l. c. 
Ueber den Einfluss der Körperbewegung auf die Magenverdauung. 569

anwenden lassen, als die, welche Ellenberger und Hofmeister bei ihren Untersuchungen stets angewendet haben. El len berger ${ }^{1}$ ) äussert sich diesbeziiglich folgenderweise: ,Abgesehen von der ersten Verdauungszeit, wihrend welcher kein Uebertritt in den Darm stattfindet, lässt sich die Berechnung der Ausgiebigkeit der Magenverdauung nur in der Weise anstellen, dass man die im Magen vorhandene Fasermenge bestimmt und dann berechnet, welche. Hafermenge der Fasermenge entspricht, wie viel Hafer also noch im Magen ist. Dann lässt sich nach Feststellung der im Magen vorhandenen unverdauten Nährstoffe leicht berechnen, wie viel Procent von den Näbrstoffen des Hafers verdaut, resp. gelöst worden, resp. aus dem Magen verschwunden sind. Man setzt dabei ein gleichmässiges Vorrücken der Inhaltstheile des Magens nach dem Darme voraus."

Diese Voraussetzung ist aber eine conditio sine qua non für die Brauchbarkeit der Ellenberger'schen Berechnungsweise. Ich wollte mich also vor allem von der Stichbaltigkeit dieser Voraussetzung überzeugen und zwar auf folgende Weise: Rückt der Mageninhalt gleichmässig in den Darm vor, so muss im Mageninhalte der absolut unverdauliche Bestandtheil desselben, die Rohfaser, in gleichem Verhältnisse stehen zum gesammten Mageninhalte resp. zu dessen Trockensubstanz, gleichviel ob der Mageninhalt langsam oder schnell weiterbefördert wird, vorausgesetzt, dass in allen Fällen ähnliche Secretmengen secernirt werden, was ibrigens bei der 'Trockensubstanz kaum in Betracht kommt, weil ja der Speichel und der Magensaft nur sehr wenig Trockensubstanz enthalten. Wir mïssen also bei allen Versuchen ähnliche Verhältnisszahlen für die Rohfaser erhalten. Ich habe diese Verhältnisszahlen für alle meine Versuche berechnet und in der folgenden Tabelle III zusammengestellt.

Nimmt man num den Mittelwerth, dieser unter einander wenig differirenden Werthe, so ergibt sich, dass bei den ruhenden Pferden das Verhältniss zwischen Mageninhalt und Rohfaser 100:3,40, bei den trabenden $100: 3,41$, bei den in Schritt bewegten $100: 3,52$, zwischen der Trockensubstanz des Mageninhaltes und Rohfaser bei den ruhenden Pferden 100: 11,37, bei den trabenden 100:12,91, bei den in Schritt bewegten $100: 12,46$ ist. - Es finden sich also

1) Ellenberger, cit. Handbuch, Bd. I. p. 834.

F. Pfiüger, Arthiv für Physiologie. Bd. 69. 
F. Tang1:

Tabelle III.

\begin{tabular}{|c|c|c|c|c|c|c|}
\hline 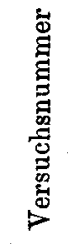 & $\begin{array}{c}\text { Art der } \\
\text { Körper- } \\
\text { bewegung }\end{array}$ & $\begin{array}{c}\text { Magen- } \\
\text { inhalt } \\
\text { gr }\end{array}$ & $\begin{array}{l}\text { Trocken- } \\
\text { substanz } \\
\text { im } \\
\text { Magen- } \\
\text { inhalt } \\
\quad \text { gr }\end{array}$ & $\begin{array}{l}\text { Rohfaser } \\
\text { im } \\
\text { Magen- } \\
\text { inbalt } \\
\text { gr }\end{array}$ & $\begin{array}{l}\text { Verhältniss } \\
\text { zwischen } \\
\text { Mageninhalt } \\
\text { und } \\
\text { Rohfaser }\end{array}$ & $\begin{array}{l}\text { Verbältniss } \\
\text { zwischen der } \\
\text { Trockensub- } \\
\text { stanz des } \\
\text { Magen- } \\
\text { inhaltes und } \\
\text { der Rohfaser }\end{array}$ \\
\hline $\begin{array}{l}\text { I. } \\
\text { II. } \\
\text { VI. }\end{array}$ & $\begin{array}{c}\text { Ruhe } \\
", \\
"\end{array}$ & $\begin{array}{l}2921 \\
2566 \\
3356\end{array}$ & $\begin{array}{l}770,4 \\
859,6 \\
999,8\end{array}$ & $\begin{array}{r}93,7 \\
102,0 \\
100,9\end{array}$ & $\begin{array}{l}100: 3,21 \\
100: 3,98 \\
100: 3,01\end{array}$ & $\begin{array}{l}100: 12,2 \\
100: 11,9 \\
100: 10,1\end{array}$ \\
\hline $\begin{array}{l}\text { III. } \\
\text { IV. } \\
\text { V. }\end{array}$ & $\begin{array}{c}\text { Trab } \\
", \\
",\end{array}$ & $\begin{array}{l}4005 \\
4604 \\
4320\end{array}$ & $\begin{array}{c}1290 \\
1221 \\
971,6\end{array}$ & $\begin{array}{l}146,8 \\
160,4 \\
132,9\end{array}$ & $\begin{array}{l}100: 3,67 \\
100: 3,48 \\
100: 3,08\end{array}$ & $\begin{array}{l}100: 11,4 \\
100: 13,4 \\
100: 13,9\end{array}$ \\
\hline $\begin{array}{l}\text { VII. } \\
\text { VIII. }\end{array}$ & $\begin{array}{c}\text { Schritt } \\
, "\end{array}$ & $\begin{array}{l}3674 \\
3460\end{array}$ & $\begin{array}{c}968,5 \\
1036\end{array}$ & $\begin{array}{l}109,4 \\
140,9\end{array}$ & $\begin{array}{l}100: 2,98 \\
100: 4,07\end{array}$ & $\begin{array}{l}100: 11,3 \\
100: 13,6\end{array}$ \\
\hline
\end{tabular}

bei allen Pferden fast dieselben Verhältnisszahlen, woraus wir wohl folgern dürfen, dass sowohl bei den bewegten als ruhenden Pferden der Mageninhalt thatsächlich gleichmässig gegen den Darm vorgeschoben wird. Diese Folgerung erscheint noch mehr berechtigt, wenn wir mit obigen Zablen das ursprïngliche Verhältniss der Rohfaser zur Gesammtmenge des mit dem Speichel vermischten Hafers und zur Trockensubstanz desselben vergleichen. Nebmen wir mit Elle n berger an, dass das Pferd beim Kauen vou $1500 \mathrm{gr}$ Hafer $3000 \mathrm{gr}$ Speichel verschluckt, so sind in diesen $4500 \mathrm{gr} 176 \mathrm{gr}$ Rohfaser entbalten, das Verbültniss ist also $100: 3,91$; der Speichel enthält etwa 1,5\% Trockensubstanz, welche mit der Trockensubstanz des Hafers zusammen $1328 \mathrm{gr}$ ausmacht; diese Trockensubstanzmenge steht zur Rohfaser wie 100:13,25. Es sind das Zahlen, welche mit den oben gefundenen sebr gnt libereinstimmen, besonders wenn man noch beriicksichtigt, dass ja auch eine gewisse Menge Magensaft producirt wird, mithin also im Mageninhalt procentisch etwas weniger Rohfaser vorhanden sein muss. Auf diese Weise ist demnach die Rohfaser unmittelbar nach dem Verschlucken in derselben relativen Menge im Mageninhalte vorhanden, wie eine Stunde später, gleichviel ob das Pferd ruhig stand oder bewegt wurde.

Auf Grund dieser Berechnungen dürfen wir also wohl mit Recht annehmen, dass die Inhaltstheile des Magens ziemlich gleichmässig nach dem Darme vorrücken, dass somit die Voraussetzung, 
auf welcher E 1 l e n b e r g e r's Berechnungsweise der Ausgiebigkeit der Magenverdauung basirt, zu Recht besteht.

Um die Ausgiebigkeit der gesammten Magenverdauung nach dieser Methode feststellen zu können, musste ausser der Rohfaser im Mageninbalte der verdaute und nnverdaute Antheil desselben bestimmt werden. Als verdaut wurde mit Ellenberger das betrachtet, was in gelöstem, als unverdaut, was in ungelöstem $\mathrm{Zu}$ stande vorhanden war. Im II. Kapitel habe ich ausführlich angegeben, in welcher Weise die Menge der gelösten und ungelösten Bestandtheile des Mageninhaltes bestimmt wurden. Aus den so ermittelten Befunden wurden dann nach der oben angegebenen Weise die Ausgiebigkeit der Magenverdaung berechnet. Leider konnte ich diese Bestimmungen nur bei 4 Pferden, bei 2 ruhenden und 2 trabenden ausführen. Die Ergebnisse weist die Tabelle IV auf.

Tabelle IV.

\begin{tabular}{|c|c|c|c|c|c|c|c|c|c|}
\hline \multirow[t]{2}{*}{ 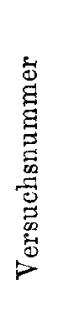 } & \multirow[t]{2}{*}{ 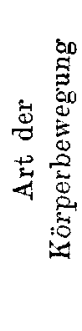 } & \multirow[t]{2}{*}{ 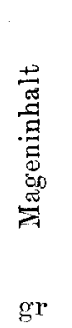 } & \multirow[t]{2}{*}{ 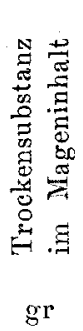 } & \multicolumn{2}{|c|}{$\begin{array}{c}\text { Von der } \\
\text { Trockensub- } \\
\text { stanz des } \\
\text { Magen- } \\
\text { inhaltes sind }\end{array}$} & \multirow[t]{2}{*}{ 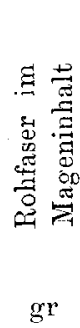 } & \multirow[t]{2}{*}{ 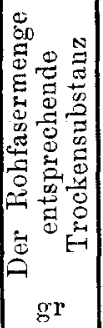 } & \multicolumn{2}{|c|}{$\begin{array}{l}\text { Von der der } \\
\text { Rohfaser ent- } \\
\text { sprechenden } \\
\text { Trockensub- } \\
\text { stanz wurden } \\
\text { also im } \\
\text { Magen ver- } \\
\text { daut }\end{array}$} \\
\hline & & & & & $r^{\prime \prime}$ & & & $g 1$ & $\%$ \\
\hline I. & & & & & & & & & \\
\hline II. & & & & 1 & 70 & 10 & 74 & 40 & \\
\hline & & & & & 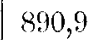 & & & & \\
\hline & & & & & & & & & \\
\hline
\end{tabular}

Das interessante Ergebniss dieser 21 Versuche ist, wie das die Daten dieser Tabelle beweisen, dass die Magenverdaung bei den bewegten Pferden 1 Stunde nach der Futteraufnahme nicht unbedeutend weiter vorgeschritten ist, als bei den rubenden. Mithinscheint die Körperbewegung bei Pferden die Magenverdau ung - wenigstens in der ersten Stundenach der Futteraufnahme-zu fordern.

Dieses Resultat ist auf den ersten Blick umso ïberraschender, als man nach den an Hunden und Menschen angestellten Versuchen eher das Gegentheil erwartet hätte. Fand doch die Mehrzahl der Autoren wie J. Cohn, Salvioli und Spirig, dass die 
Magenverdauung durch die Körperbewegung verzögert wird; und auch Streng sagt nur, dass die Magenverdaunng durch die Körperbewegung nicht beeinflusst wird.

Unser Resultat verliert jedoch an seiner Auffälligkeit, wenn man erstens in Betracht zieht, dass die Untersuchungen der angeführten Autoren eirerseits an Fleischfressern angestellt wurden, anderseits beim Menschen auch nur die Eiweissverdaung berücksichtigt wurde, während wir an Pferden experimentirten, deren Magenverdauung nach den Untersuchungen von Ellen berger und Ho fmeister ${ }^{1}$ ) und Goldschmidt nicht unwesentlich von der der Fleischfresser abweicht. Nach diesen Forschern - und ich kann nach meinen Erfahrungen ihre Angaben nur bestätigen, - werden beim Pferde in der ersten Periode der Magenverdaung fast nur Kohlehydrate verdaut, die Eiweissverdaung ist nur eine ganz geringe. Ell en berger nennt auch dem entsprechend diesen ersten Abschnitt der Magenverdaung "die amylolytische Periode." Diese Periode danert - nach Elle n b e rge r 1-2-3 Stunden, die Dauer der Mahlzeit mitgerechnet 2-3-4 Stunden. Die lange Dauer dieser amylolytischen Periode erklärt die grosse Menge des verschluckten alkalischen Speichels, so dass „eine lange Zeit verstreicht, ehe so viel Süure secernirt ist, um eine derartige Concentration derselben im Mageninhalte zu bedingen, welche die Zuckerbildung hindert" (E I l e n b e r g e r).

Bei den bewegten Pferden entleert sich nun der Magen langsamer, es bleibt ein grösserer Theil des alkalischen Speichels im Magen zuriick, es wird also eine grössere Menge der producirten Säure nentralisirt. Der Mageninbalt bleibt -- wie wir oben saben - alkalisch, was auf die Saccharificirung der Stärke nur förderlich wirken kann. Diese Ueberlegung legt es schon a priori nábe, dass unter solchen Umständen mehr Stärke gelöst werden kann, dass also die grössere Ausgiebigkeit der Magenverdaumg bei den bewegten Pferden wahrscheinlich durch eine intensivere Verzuckerung der Stärke bedingt sei. Diese Vermathung wurde durch die directe Prifung der Kohlehydratverdaung bestätigt. Diese Prüfung konnte leider, wie schon einmal erwähnt, nur in 2 Ver-

1) Ellenberger u. Hofmeister, Ueber die Verdaunngssäfte und Verdauung des Pferdes. (Arch. f. wiss. u. prakt. Thierheilkunde. Bd. VIII bis XII.) 
suchen ausgeftihrt werden bei einem rubenden und einem trabenden Pferde. Bestimmt wurde im Mageninhalte - nach der im Kapitel II. beschriebenen Methode - die Menge der vorhandenen ungelösten und gelösten Kohlehydrate. (Der Einfachheit halber sind, wie bereits erwähnt, ungelöste und gelöste Kohlehydrate als Dextrose berechnet). Wie bei der Gesammtverdauung des Magens wurde dann berechnet, wie viel von den der im Magen vorhandenen Rohfaser entsprechenden Kohlebydraten noch in unverdautem (ungelöstem) Zustande vorhanden ist. Die folgende Tabelle zeigt die Resultate:

Tabelle V.

\begin{tabular}{|c|c|c|c|c|c|c|c|c|}
\hline \multirow[t]{2}{*}{ 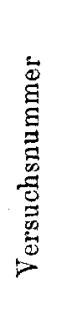 } & \multirow[t]{2}{*}{ 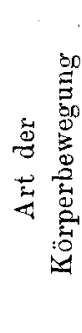 } & \multirow[t]{2}{*}{ 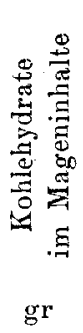 } & \multicolumn{2}{|c|}{$\begin{array}{l}\text { Von den } \\
\text { Kohle- } \\
\text { hydraten } \\
\text { sind }\end{array}$} & \multirow[t]{2}{*}{ 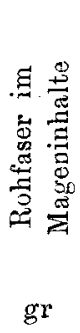 } & \multirow[t]{2}{*}{ 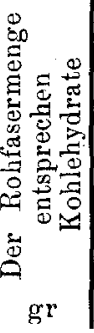 } & \multicolumn{2}{|c|}{$\begin{array}{l}\text { Von den der } \\
\text { Rohfaser- } \\
\text { menge } \\
\text { entsprechen- } \\
\text { den Kohle- } \\
\text { hydraten } \\
\text { wurden also } \\
\text { im Magen } \\
\text { verdaut }\end{array}$} \\
\hline & & & 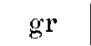 & 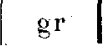 & & & $\mathrm{gr}$ & \\
\hline & & & & & & & 10, & \\
\hline & rat & 59,2 & 172,8 & 496,4 & 146,8 & 621,1 & 134,7 & 21, \\
\hline
\end{tabular}

Es sind beim trabenden Pferde nicht nur absolut mehr Kohlehydrate verdant worden, weil im Magen mehr zuriekblieb, sondern es wurde anch ein relativ grösserer Theil derselben verdant. Diese zwei Versuche bestätigen also unsere Vermuthung; bei dem trabenden Pfcrde, ist ein grösserer Theil der Kohlehydrate im Magen verdaut worden, als bei dem ruhenden. Der Unterschied ist sehr bedeutend: während bei dem trabenden Pferde 21,7\%, wurden beim ruhenden nur $7,79 \%$ der Kohlehydrate verdaut. Dieser Unterschied in der Kohlehydratverdaunng ist so gross, dass es wohl allein, diein den Versuchen III u. IV constatirte, grössere Ausgiebigkeit der gesammten Magenverdaung des trabendes Pferdes bedingt, was um so wahrscheinlicher ist, als einerseits, wie bereits erwähnt wurde, in dieser Periode fast allein nur die Kohlehydrate verdautwerden und anderseits die Kohlehydrate auch den grössten Theil der Trockensubstanz des Hafers ausmachen. Wenn auch diese 2 Versuche allein keinen endgültigen Beweis fübren können 
574 F. Tangl: Ueb. d. Einfl. d. Körperbewegung auf d. Magenverdanung.

so gewinnen sie durch den Umstand doch nicht wenig an Beweiskraft, dass ihre Resultate eben mit den Daten über die Gesammtverdauung dieser Versuche sehr gut ibereinstimmmen.

Unsere Versuche führen uns somit zu dem Schlusse, dass während der Körperbewegung (Trab) d i M a genverdaung des Pferdes in der ersten Stunde nach der Futteraufnahmeeineausgiebigere und dass diegrössereAusgiebigkeit dureh die intensivere Verdaung der Stärke bedingt ist. Die Körperbewegung (Trab) unmittelbar nach der Futteraufnahme fördert also beim Pferde die Verdauung der Kohlehydrate im Magen.

Zur Entscheidung der Frage, wie sich die Magenverdauung der Eiweissstoffe während der Körperbewegung verbält, konnten meine Versuche nicht verwendet werden. (S. Kapitel II.). Sie wären dazu auch nicht geeignet gewesen, weil in der ersten Periode der Magenverdauung, der amylolytischen, nur sehr wenig Eiweiss verdaut wird. Dazu müssten spätere Stadien der Magenverdauung untersucht werden. (Uebrigens habe ich mich durch qualitative Priufung des Mageninhalts der rubenden und der bewegten Pferde ibberzeugen können, dass auch in der anylolytischen Periode, wie Ellenberger und Goldschmidt angeben, etwas Eiweiss verdaut wird. Ich konnte Syntonin, Albumosen und Pepton nachweisen.)

Ebenso wenig geben diese Versuche Aufschluss über das Verhalten resp. die eventuelle Veränderung der Resorptionsfähigkeit der Magenschleimhaut während der Ruhe und der Körperbewegung.

Ueberblicken wir nun zum Schlusse die Resultate unserer Versuche, so glaube ich aus ihnen, trotz ihrer Unvollständigkeit, doch so viel folgern zu können, dass beim Pferde die Motilität, die secretorische Thätigkeit des Magens und die Verdauungsvorgänge in demselben von den Körperbewegungen in der besprochenen Weise beeinflusst werden. Der ermittelte Einfluss bezieht sich allerdings nur auf die erste Periode der Magenverdaung und es ist noch zu untersuchen, wic sich die späteren Stadien der Magenverdauung verhalten. 